Gibson, Stephen ORCID:

https://orcid.org/0000-0002-5648-7669 (2012) 'I'm not a war monger but...': Discourse Analysis and Social Psychological Peace Research. Journal of Community \& Applied Social Psychology, 22 (2). pp. 159-173.

Downloaded from: http://ray.yorksj.ac.uk/id/eprint/599/

The version presented here may differ from the published version or version of record. If you intend to cite from the work you are advised to consult the publisher's version:

Research at York St John (RaY) is an institutional repository. It supports the principles of open access by making the research outputs of the University available in digital form. Copyright of the items stored in RaY reside with the authors and/or other copyright owners. Users may access full text items free of charge, and may download a copy for private study or non-commercial research. For further reuse terms, see licence terms governing individual outputs. Institutional Repository Policy Statement

\title{
RaY
}

Research at the University of York St John

For more information please contact RaY at ray@yorksj.ac.uk 
Running head: DISCOURSE ANALYSIS AND PEACE RESEARCH

'I'm not a war monger but...': Discourse Analysis and Social Psychological Peace Research

\section{Stephen Gibson}

York St John University

Acknowledgments: I would like to acknowledge the assistance of Rebecca Barry in the preparation of transcripts for use in the analysis, and two anonymous reviewers for their constructive comments on an earlier version of this manuscript. The analysis reported in this paper was presented in departmental seminars at the Universities of Lancaster, Limerick and Nottingham Trent during 2009, as well as at the International Society of Political Psychology's 32 ${ }^{\text {nd }}$ Annual Scientific Meeting, Dublin, July 2009. I would like to thank audience members at these presentations for their many insightful comments. Extracts from transcripts of 'Question Time' are reproduced by permission of the BBC.

Correspondence concerning this article should be addressed to Stephen Gibson, Faculty of Health \& Life Sciences, York St John University, Lord Mayor's Walk, York, YO31 7EX, UK. E-mail: s.gibson@yorksj.ac.uk 


\begin{abstract}
The present paper argues for a discourse analytic approach to social psychological peace research, and demonstrates the potential of such an approach through a respecification of the concept of attitudes to war. This is illustrated through an analysis of a series of televised debates broadcast in the UK in February-March 2003, in the build-up to the formal outbreak of the Iraq War. Analysis draws attention to the importance of rhetorical context and function, the inseparability of attitude object and evaluation, and the formulation of evaluations as specific or general. Findings are discussed in the context of recent calls for methodological pluralism in social psychological peace research, with a suggestion that matters of epistemology stand prior to methodology.
\end{abstract}

Keywords: attitudes, discourse analysis, Iraq, peace, rhetoric, war 
'I'm not a war monger but...': Discourse Analysis and Social Psychological Peace Research

In their recent review of social psychological contributions to the study of peace and conflict, Vollhardt and Bilali (2008) point to a large degree of overlap between the concerns of social psychologists, and those of peace psychologists. In particular, they identify a range of social psychological concepts and topics, such as prejudice, social identity, and social dominance, which are directly relevant to the emerging field of Peace Psychology (see e.g. Blumberg, Hare \& Costin, 2006). They also draw attention to the range of methodological approaches employed in social psychological peace research (SPPR), which they point out is more diverse than in social psychology as a whole. Nevertheless, they acknowledge that experimental and survey techniques are still dominant - together accounting for $61 \%$ of the methodological techniques used in the papers they reviewed - and call for more pluralistic methodological approaches to be adopted. At one point they even speculate that 'the use of multiple methods ... could be proposed as an explicit criterion in future conceptualizations of SPPR' (Vollhardt \& Bilali, 2008, p. 21), and go on to argue that, 'the field could dig even deeper into its conceptual and methodological toolbox when studying these issues and could give more attention to certain criteria during the selection of research questions, operationalizations, and methodologies' (p. 22).

The present article echoes Vollhardt and Bilali's call to 'dig deeper', and aims to illustrate some of the ways in which social psychologists might do so in SPPR. Specifically, the present paper aims to illustrate the potential utility of Discourse Analysis (henceforth sometimes DA) as an approach which forms a part of social psychology's 'conceptual and methodological toolbox' for addressing issues of peace 
and conflict, with a particular focus on the area of attitudes to war. However, in developing these arguments a cautionary note is also sounded about the prospects of using DA in a straightforward manner alongside experimental or survey techniques. Such pluralism requires a careful attention to epistemological concerns, and points to the close connection between theory and method. Indeed, as has been argued in relation to psychology more broadly (e.g. Edwards \& Potter, 1992; Pottter \& Wetherell, 1987), adopting a discourse analytic approach presents a challenge to more conventional methods such as survey techniques. In this respect, DA can be understood not simply as another way of addressing familiar problems, but as involving a fundamental re-specification of the discipline.

\section{Attitudes to war}

One of the key areas of research for SPPR, as for Peace Psychology more generally, has been the study of attitudes associated with peace, conflict and related matters. In this literature, two broad types of measure can be identified. On the one hand are measures of attitudes to war in general, which are sometimes measured using scales of militarism-pacifism (e.g. Cohrs \& Moschner, 2002), or which may sometimes form parts of more general measures of attitudes to violence (e.g. Anderson, Benjamin, Wood, \& Bonacci, 2006). On the other hand are measures of attitudes towards specific wars, such as the Vietnam War (e.g. Sherman, 1973), the Iraq War (e.g. McFarland, 2005; Roccato \& Fedi, 2007; Stapel \& Marx, 2007) and the Kosovo War (e.g. Cohrs \& Moschner, 2002). It is not uncommon for researchers to explore the relationship between these two types of measure, or their relationship with other psychometric variables. For example, Cohrs, Moschner, Maes and Kielmann (2005) found that attitudes to war in general, attitudes to the Afghanistan War and 
attitudes to the Kosovo War were all negatively related to values of universalism and benevolence, and positively related to values of power, conformity and security. Similarly, Cohrs and Moschner (2002) found a positive correlation between attitudes to the Kosovo War and general militaristic attitudes.

This tradition of work has borrowed largely from mainstream attitude theory and measurement, which has come in for a certain amount of criticism over the past twenty years or so from social psychologists adopting discourse analytic perspectives (e.g. Billig, 1996; Durrheim \& Dixon, 2004; Potter, 1998; Potter \& Wetherell, 1987). Discourse analytic approaches emphasise the importance of attending to the way in which people formulate evaluations of attitude objects in discursive practice. Indeed, it has been argued that once we re-specify the study of attitudes in this way, the idea of an attitude object existing independently from evaluations of it is difficult to sustain.

However, the present concern is not solely with the potential of DA to enrich SPPR, but also to begin to open up a new field of investigation for discourse analytic research in social psychology. Despite the existence of a well-developed literature on language and war in other disciplines (e.g. Jackson, 2005; Lakoff, 1990; Schäffner \& Wenden, 1995; van Dijk, 2005), this rarely addresses specifically psychological matters. By contrast, although DA has developed within social psychology in a way that has already involved a close engagement with concerns which are central to Vollhardt and Bilali's (2008) conception of social psychological peace research, such as intergroup relations, prejudice and nationalism, there has as yet been little attempt at a systematic programme of research directed at matters of warfare and military conflict (for exceptions, see Billig \& MacMillan 2005; Gibson \& Abell, 2004; Gibson \& Condor, 2009; Herrera, 2003; McKenzie, 2001). It is this which is the concern of 
the present paper - the application of discourse analysis to matters of international military conflict.

\section{Discourse, attitudes and evaluations}

The approach adopted in the present paper draws on insights from a range of complementary traditions, such as the discourse analytic approach outlined by Potter and Wetherell (1987), the discursive psychology of Edwards and Potter (1992), and Billig's (1996) rhetorical psychology. For the sake of simplicity, the approach will be referred to simply as discourse analysis, and although the present paper is not the place to rehearse them in detail, it should be noted that there are important debates of theory and method amongst discursive researchers (see e.g. Griffin, 2007; Potter \& Hepburn, 2005; Wetherell, 1998). Therefore, without wishing to gloss over some important differences between approaches it is worth outlining in more detail the implications of this work for the study of attitudes.

As a social constructionist approach, DA emphasises the discursive construction of reality, including psychological reality. This has particular implications for attitude research. Conventionally, the attitude object and dimension of judgement are treated as separate constructs. However, Potter and Wetherell (1987) argued that a consideration of the construction of evaluative statements in discourse makes this distinction difficult to sustain. For example, Billig (1996) discussed a report of then US President Ronald Reagan taking exception to the description of the deployment of US forces in Grenada in 1983 as an 'invasion', instead glossing it as a 'rescue mission'. Billig (1996, p. 173) noted that:

Such is the rhetorical force of language that the very choice of terms implies a position. In consequence, it becomes impossible to talk about an invasion 
without implicitly or explicitly signalling a stance. Even a choice of ostentatiously neutral terms would indicate a position, for neutrality in the midst of conflict is every bit as much a position - and a controversial one at that - as is partisanship.

Thus rather than being separate from the dimension of judgement, the description of the attitude object carries its evaluative connotations with it.

Furthermore, Potter and Wetherell (1987) argued that speakers construct objects in certain ways in order to perform particular actions, and in this respect discourse is inherently action-oriented, or functional. Reagan's construction of the involvement of US forces in Grenada as a 'rescue mission' functions to position the intervention as an essentially humanitarian one, conducted with the best of intentions, and to manage the impression that the President himself might be inclined to engage in morally questionable military adventures. Of course, in another context Reagan may have used quite different terms. In this respect, discourse analysts have been concerned with the way in which evaluations are situated - that is, the ways in which discourse is occasioned by, and situated in, the context of its production (see e.g. Potter \& Edwards, 2001).

Underpinning DA is a conceptualization of discourse as fundamentally rhetorical (Billig, 1996). When speakers offer an evaluation, they are rhetorically working up that evaluation as convincing in contrast to other, frequently unstated, alternatives. Similarly, when a speaker is constructing an object, we should expect to find rhetorical devices aimed at establishing the factual nature of that construction, and to undermine possible alternative constructions (Potter, 1996). Related to this is the management of stake and interest (Edwards \& Potter, 1992) - the ways in which 
speakers can attend to their own position and involvement in the matter under discussion.

Discourse analysts have therefore argued that the study of attitudes might usefully be re-conceptualized as the study of how evaluations get done in practice, with attention being paid to the way in which such evaluations are rhetorically constructed to perform particular functions in particular contexts. Given that the DA approach to attitudes has yet to be applied to the study of attitudes to war, it is the aim of the present paper to sketch some of the possibilities of such an approach through an analysis of the rhetorical construction of evaluative statements in a series of televised debates concerning the Iraq War.

Data

The data which form the material for analysis in the present study are taken from a corpus of television discussion programmes recorded from UK television in March 2003 in the build up to, and early stages of, the Iraq War. The present analysis concerns a sub-set of these recordings, which consists of six episodes of the British Broadcasting Corporation's (BBC) current affairs discussion programme 'Question Time', shown on the channel BBC1 between $13^{\text {th }}$ February and $20^{\text {th }}$ March 2003. This sub-set covers the time period leading up to the formal declaration of hostilities, which occurred on $20^{\text {th }}$ March. The basic format of the 'Question Time' programme involves a panel of guests - which usually consists of politicians, journalists and other commentators - who are invited by the host (David Dimbleby) to respond to questions posed by members of the general public who are present in the studio audience. At various points in the programme, audience members are also invited to speak, albeit they are typically required to do so in a much briefer manner than the panel members. 
Each programme lasts around an hour, with several topical political issues being discussed. For the present analysis, relevant portions of the programmes (i.e. those sections featuring discussion of Iraq) were selected and transcribed in an abbreviated form of Jeffersonian transcription notation (see Hutchby \& Wooffitt, 1998). A guide to transcription conventions and speaker identification in the extracts presented in the analysis section can be found in the Appendix.

Initial data coding involved careful reading and re-reading of transcripts to identify all instances in which speakers were offering an evaluative statement on war in general, the Iraq War in particular, or indeed on any other related objects or events. Analysis proceeded in accordance with the principles of DA as outlined above. As Potter (1998, p. 239) notes, '[t]here is no single simple recipe for analysing discourse', but the present research followed the guidelines provided by Potter and Wetherell (1987) and Wiggins and Potter (2008).

\section{Analysis}

It was apparent that evaluations of this specific war made relevant evaluations of a range of associated phenomena, such as war in general, tyranny, and US foreign policy. Similarly, as discourse analysts have long argued (e.g. Potter \& Wetherell, 1987), evaluations were built into the very construction of what might be termed attitude objects. This section explores these issues in some detail.

The analysis pointed to an interesting rhetorical strategy in which speakers who were arguing for military action in Iraq used a disclaimer (Hewitt \& Stokes, 1975) in order to position themselves as not dispositionally inclined to favour war, before then going on to argue in favour of military intervention. For example: 


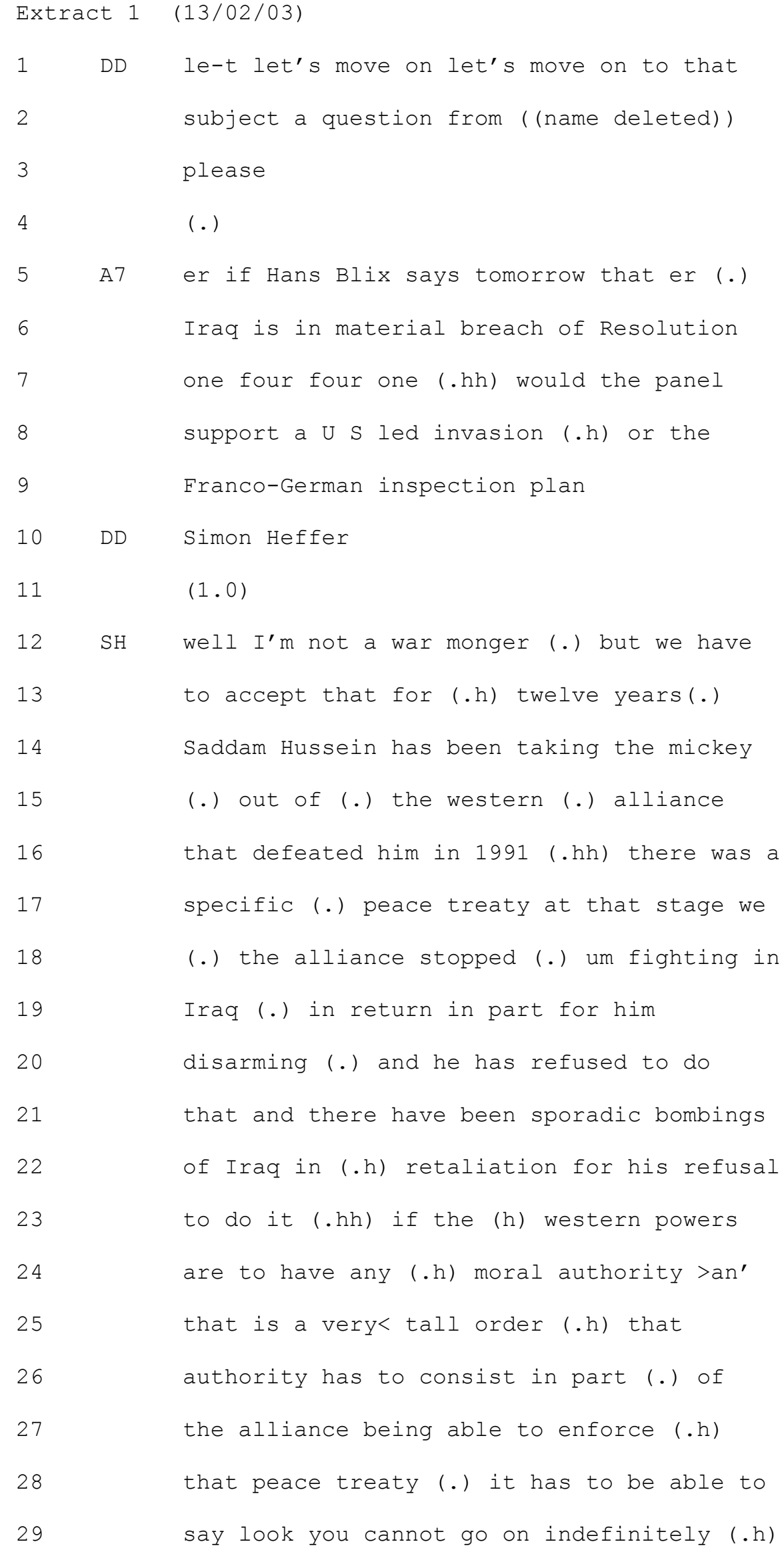




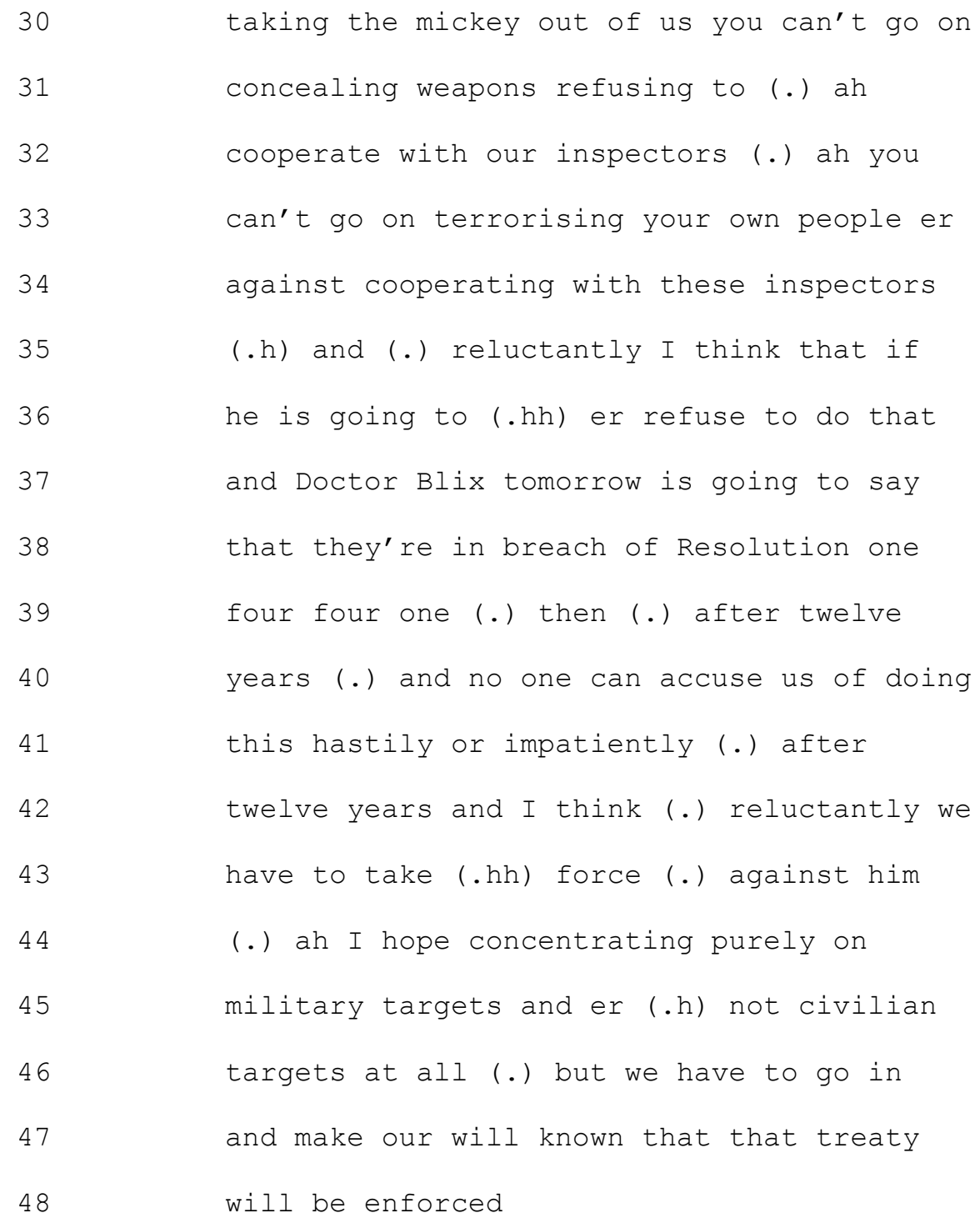

Three things are worthy of note about this extract. First, it is apparent that A7's question is not a neutral request for panel members to indicate the side of the debate on which they stand, but in fact constructs the terms of the debate as involving a choice between 'invasion' and 'inspection' (11. 8-9). This illustrates Potter and Wetherell's (1987) point concerning the way in which evaluations are routinely built into what social psychologists would typically describe as attitude objects. Compare, for example, the opposing evaluative glosses provided by the hypothetical alternatives 'liberation' and 'appeasement'. Although this question provides the immediately preceding interactional context for Simon Heffer's extended turn beginning on line 
12 , Heffer's account is also, of course, a contribution to a broadcast discussion watched by millions of viewers. In this context, his opening utterance 'I'm not a war monger (.) but' is significant in that it constitutes a disclaimer - a denial of an unstated proposition designed to ward off potentially negative inferences concerning his general disposition in matters of war (i.e. that he is the sort of person who typically agitates for conflict). Such disclaimers are well documented in a variety of contexts (see e.g. Augoustinos \& Every, 2010; Condor, Figgou, Abell, Gibson \& Stevenson, 2006; van Dijk, 1992), and mark the speaker as orienting to what he is about to say as potentially making available the inference that he is, indeed, a 'war monger'. The rhetorical effectiveness of such utterances is, of course, a matter for recipients, but the logic of disclaimers is effectively to construct the speaker as not being the sort of person who one would typically expect to be taking this particular line of argument. Someone who can be glossed as a 'war monger' can be dismissed fairly readily by opponents, and to construct oneself as not dispositionally inclined to favour war is to anticipate, and potentially to ward off, such dismissals.

Second, it is also interesting to note that Heffer's stake inoculation work (Edwards \& Potter, 1992) does not end with his disclaimer on line 12, but continues throughout his turn. To provide just a few examples, Heffer constructs his position as one that is taken 'reluctantly' $(1.35 ; 1.42)$, and refers to the precise length of time (1.13; 11. 39-40; 11. 41-2: 'twelve years') since the previous war with Iraq. He uses a further disclaimer on behalf of the collective 'western alliance' (11. 40-41: 'no one can accuse us of doing this hastily or impatiently'), and confesses a 'hope' for 'concentrating purely on military targets and er (.h) not civilian targets at all' (11. 446). The use of the psychological term 'hope' is potentially significant here. 'Hope' implies a sincerely held wish, but one that may not necessarily be expected to come to 
fruition. In this respect, the use of the terms 'purely' and 'at all' in this formulation serve to mark his 'hope' as being for an absolute focus on military rather than civilian targets. These extreme case formulations (ECFs; Pomerantz, 1986) enable Heffer to construct his position as an essentially morally normative one (military targets are legitimate, civilian targets are not), whilst implicitly acknowledging (through the use of 'hope') that such an ideal scenario is unlikely.

Finally, the initial terms of the question ('invasion' versus 'inspection') are resisted. Heffer constructs the action he is arguing for not as an 'invasion', or indeed as a 'war', but as 'enforce[ment]' of a 'peace treaty' (11. 27-8; 11. 47-8). This is again an example of the way in which the speakers are not simply offering different evaluations of the same object, but are actually constructing the very nature of that object as, on the one hand, an invasion, and on the other as the enforcement of a peace treaty. This striking construction is part of Heffer's broader rhetorical project of holding Saddam Hussein accountable for the necessity of such 'enforcement': note how Hussein is constructed as, amongst other things, 'taking the mickey' (1. 14; 1. 30), refusing to disarm (11. 19-21), and, in the collective hypothetical voice (Myers, 1999) of 'the western alliance', as 'terrorising your own people' (1.33) and 'concealing weapons' (1. 31). All these devices serve to rhetorically mark Hussein's responsibility, and to minimise the accountability of the 'western alliance.'

The extended speaking turn granted to Heffer by virtue of his position as a panellist allows him to construct an elaborate series of rhetorical moves in favour of 'enforcement'. In this respect, his disclaimer ('I'm not a war monger but ...') constitutes only the initial part of his extended rhetorical strategy of presenting his position as one of reluctant support for the war. In contrast, audience members had less time to make their point. In the following extract, a member of the audience 
prefaces her disclaimer with a pair of identity claims (Antaki, Condor \& Levine, 1996; Antaki \& Widdicombe, 1998):

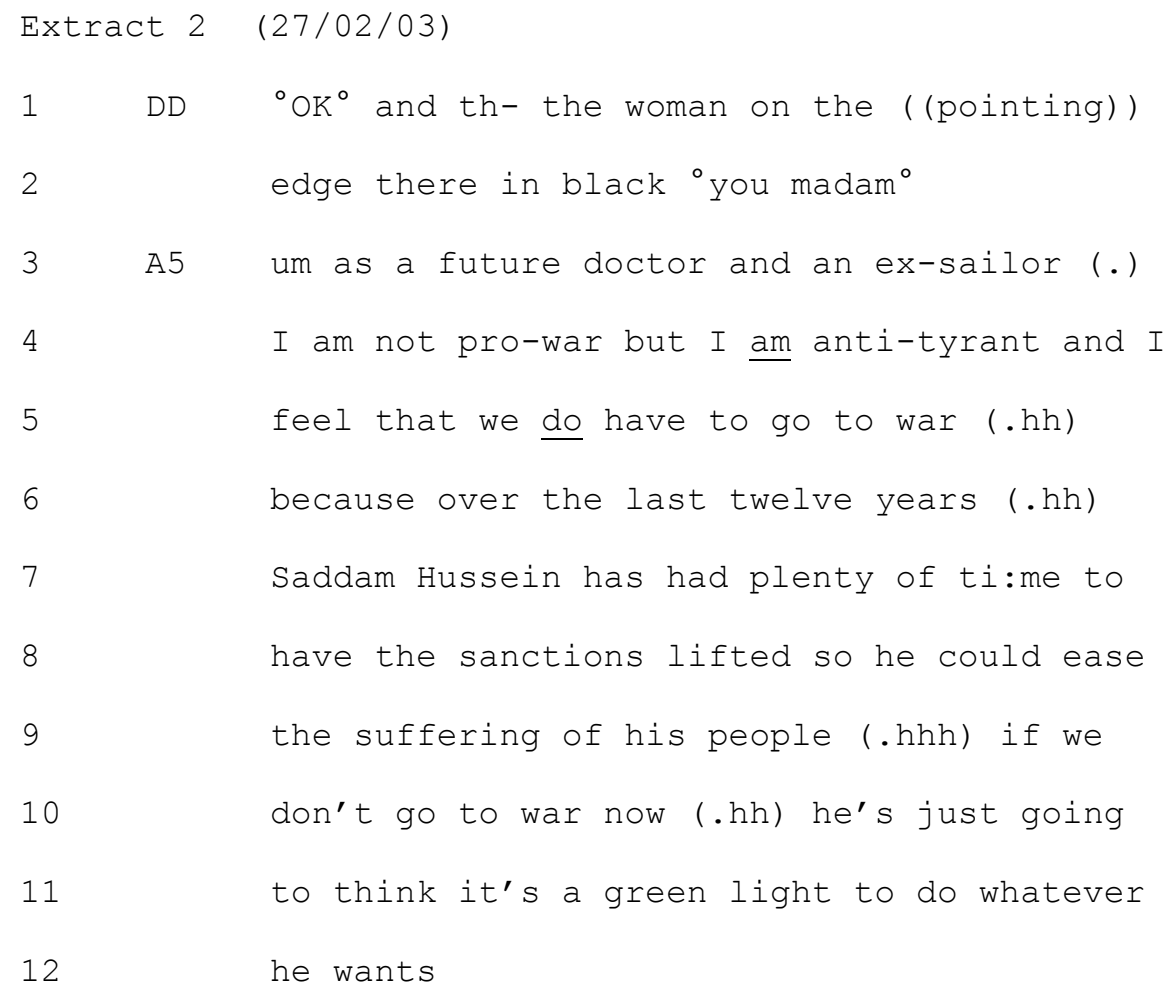

A5's identity avowal marks her position as one that is offered from the vantage point of 'a future doctor and an ex-sailor', and functions to buttress the claim that she is 'not pro-war' (lines 3-4). In this context, these identities are invoked to establish the speaker's non-pro-war credentials, and to demonstrate, over and above the disclaimer itself, that the speaker has category entitlement to claim such a non-pro-war identity. She goes on to gloss her position as being 'anti-tyrant', thereby arguing in favour of war in a way which neatly inoculates against the inference that she is routinely inclined to favour war, whilst simultaneously claiming a dispositional opposition to tyranny. In one sense, this claim to be 'anti-tyrant' may seem rhetorically problematic for the speaker in so far as it potentially allows opponents to dismiss her as just the 
sort of person who one would expect to argue in favour of military action against

Saddam Hussein. However, such an objection may prove rhetorically troublesome for potential opponents given the opprobrium which would be attached to arguments that could be glossed as 'pro-tyrant'.

Indeed, the opprobrium which could be attached, on the one hand, to a straightforward desire for war, and on the other, to anything that could be glossed as being favourable towards Saddam Hussein, is apparent in extract 3, in which panel members are responding to a question concerning the plans for the aftermath of the war, with particular reference to the Kurdish people:

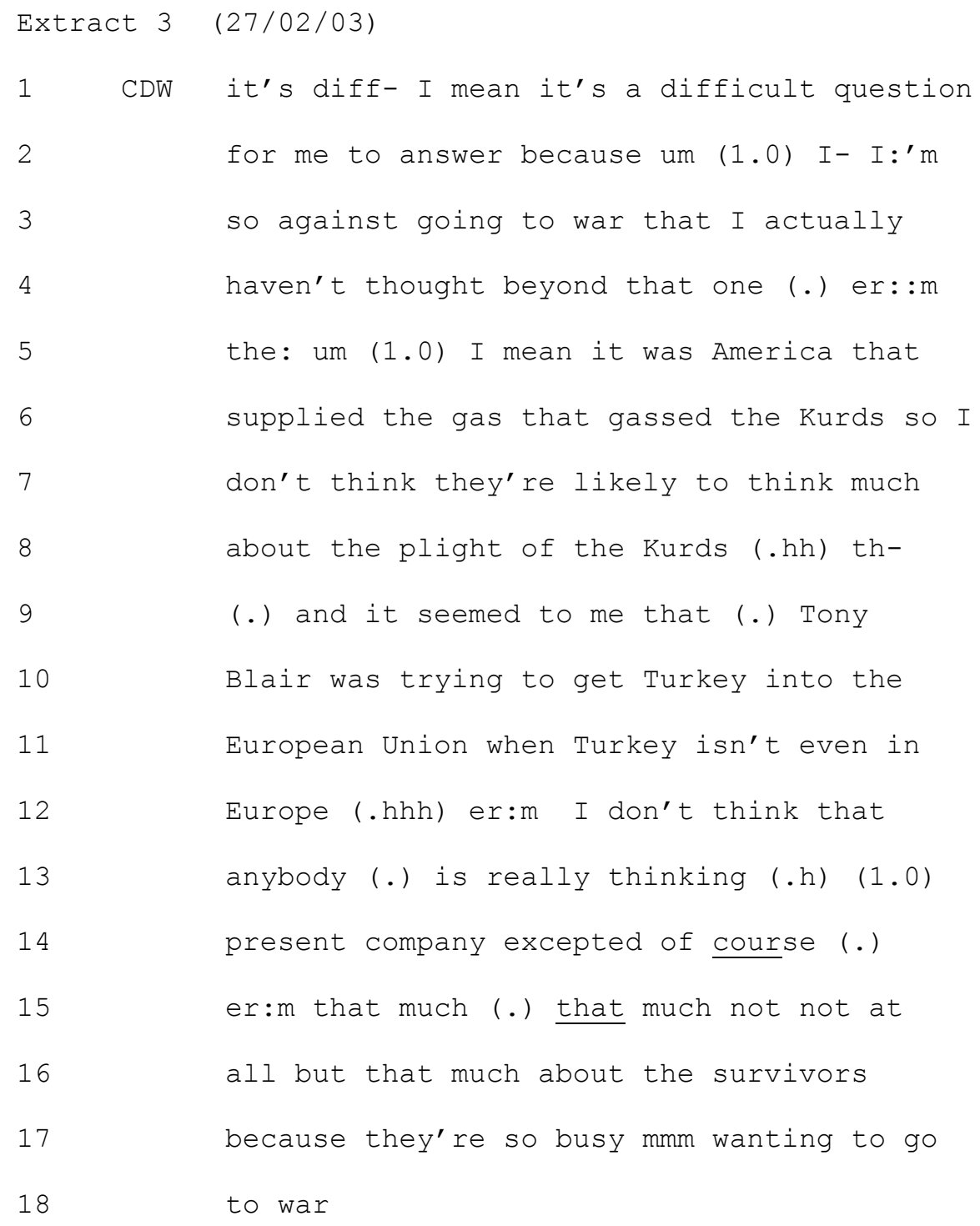




\begin{tabular}{|c|c|c|}
\hline 19 & $\mathrm{DD}$ & Bea Campbell \\
\hline 20 & $\mathrm{BC}$ & $(. h h)$ (.) I think you: you've hit on a \\
\hline 21 & & really really important question (.) erm I \\
\hline 22 & & would fear (1.0) for the Kurds and I'm sure \\
\hline 23 & & that they're currently fearing (.) for \\
\hline 24 & & themselves (.hhh) what's at stake here \\
\hline 25 & & after all (.hh) is not the liberation \\
\hline 26 & & of people in Iraq but the establishment of \\
\hline 27 & & (.) what is called the new imperialism (.h) \\
\hline 28 & & promoted by Bush and the United States \\
\hline 29 & & $(. \mathrm{hh}){ }^{\circ} \mathrm{but}{ }^{\circ}$ \\
\hline 30 & $\mathrm{TC}$ & for goodness sake \\
\hline 31 & $\mathrm{BC}$ & do you mind! \\
\hline 32 & $\mathrm{Au}$ & $(($ laughter $))$ \\
\hline 33 & $\mathrm{TC}$ & no yes I do [mind (.) I do mind (.) if \\
\hline 34 & & you don't think] \\
\hline 35 & $\mathrm{BC}$ & [oh well ((inaudible)) ] \\
\hline 36 & $\mathrm{Au}$ & {$[((\operatorname{applause} 3.0))]$} \\
\hline 37 & $\mathrm{TC}$ & [that almost any government would be (.) a \\
\hline 38 & & liberation] \\
\hline 39 & $\mathrm{Au}$ & $(($ applause) ) \\
\hline 40 & $\mathrm{TC}$ & compared to Saddam Hussein I worry about \\
\hline & & you Bea I really do \\
\hline
\end{tabular}

There is clearly a great deal that could be said about this extract, but of particular relevance for present purposes are lines $2-3,12-18$ and 33-41. The first speaker, Clarissa Dickson-Wright, explains her self-professed difficulty in discussing this issue as being because 'I'm so against going to war' (11. 2-3). Note how this positional statement is delivered in a relatively straightforward manner, despite the hesitancy that precedes it on lines 1-2. There is, for example, no disclaimer or supporting 
identity claim associated with this positional statement, and there is little evidence elsewhere in the turn that this is hedged or qualified in any way. She does not, for instance, position herself as a reluctant opponent of the war. It seems reasonable to suggest, therefore, that this positional statement is used to manage the delicate task of not answering the question, rather than being the source of any interactional trouble itself.

Subsequently, Dickson-Wright suggests that nobody (specifically 'America' and Tony Blair) is concerned for 'the survivors [of the anticipated war]' because 'they're so busy ... wanting to go to war' (11. 17-19). This use of the straightforward desire to wage war as a way of holding social actors to account is an accusation of precisely the sort of premature, unrestrained, unthinking thirst for conflict that the speakers in extracts 1 and 2 can be seen to be rhetorically inoculating themselves against. Note also how the accusation draws on themes of lack of reasoned thought (11 12-13: 'I don't think that anybody (.) is really thinking') which helps to position those who are 'busy ... wanting to go to war' as irrationally failing to think through the consequences of their actions.

If the conclusion of Dickson-Wright's turn can be seen as illustrating the sorts of accusations which potentially awaited advocates of war, the exchange between Beatrix Campbell and Tim Collins on lines 33-41 is indicative of the way in which accusations of being favourable towards Saddam Hussein could be levelled at opponents of the war. Collins challenges Campbell's assertion of a 'new imperialism promoted by [George W.] Bush and the United States' (11. 27-8) with a counterargument that 'almost any government would be a liberation compared to Saddam Hussein' (11. 37-40). Again, rationality and morality are made relevant in the suggestion that if this is not what she thinks then it is a cause for 'worry' (1. 40). 
Here, then, we see that (a) a pro-war position is treated as accountable (by both advocates and opponents) to the extent to which it appears to betray an unthinking and unseemly haste to engage in conflict, (b) opponents of the war do not appear to need to engage in the sort of identity management work when stating their basic position in the same way that advocates of the war do, but (c) advocates of the war can hold opponents accountable by constructing them as holding a morally questionable position regarding Saddam Hussein. Indeed, such accusations were anticipated by several speakers in the dataset arguing against going to war in Iraq. For example, in extract 4 - in which Clive Anderson is about to argue for caution the glossing of Saddam Hussein as 'evil' and a 'gangster' functions to inoculate the speaker from accusations of leniency:

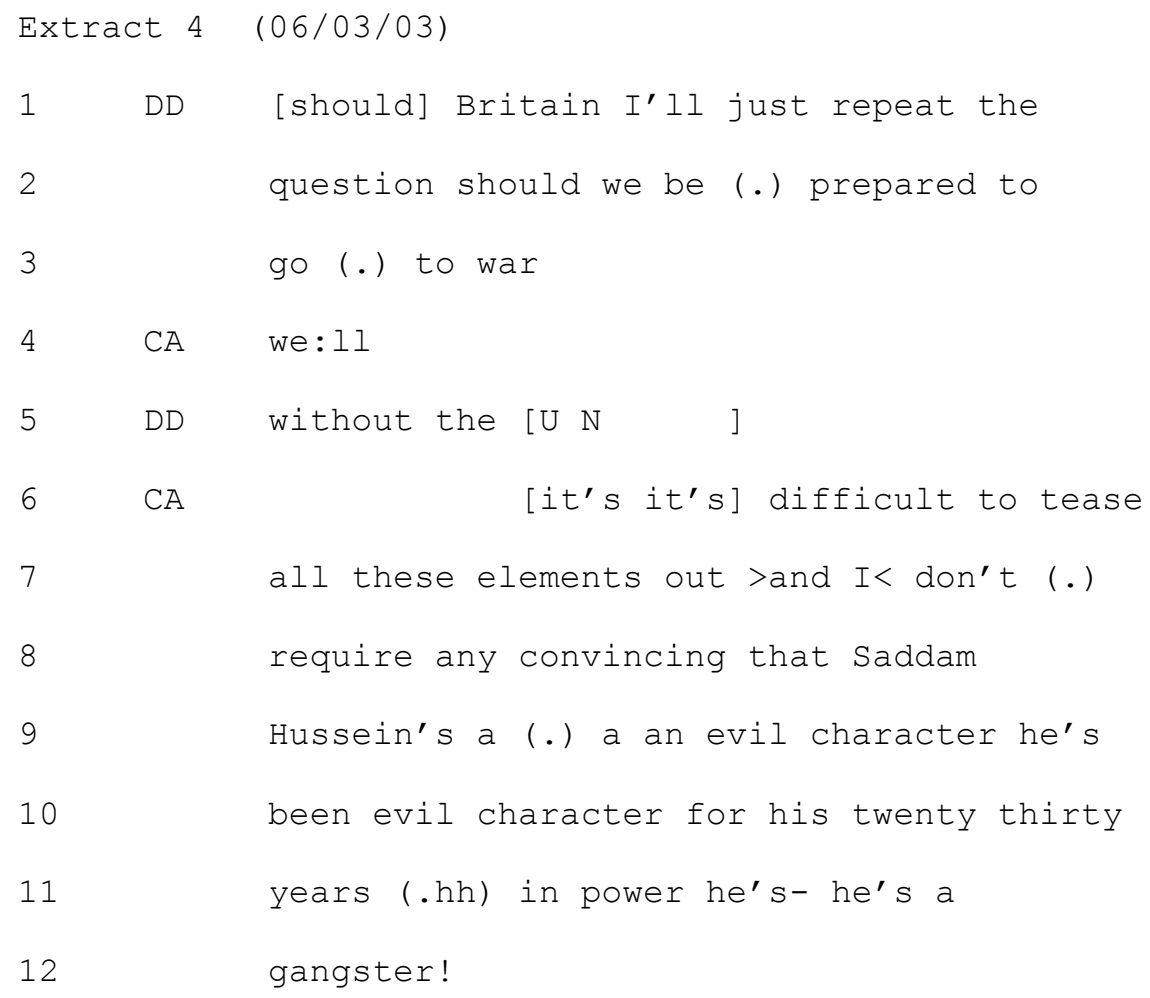

Anderson prefaces his argument for caution with a suggestion that it is 'difficult to tease all these elements out' (11. 6-7), a formulation which avoids a straightforward 
response to the question. In this context, his subsequent assertion that he 'doesn't need any convincing' about Saddam Hussein's character serves quite literally to anticipate and circumvent any attempt to 'convince' him in a similar fashion to extract 3 above.

The analysis highlights how these arguments concerning the war in Iraq entail a range of identity management projects on the part of speakers. Whereas advocates of war could find themselves accused of, and inoculate themselves against, a habitual preference for military conflict, opponents of war did not have to disclaim a generally anti-war outlook, but instead could find themselves accused of, and inoculate themselves against, a generally lax moral position with regard to Saddam Hussein. This is not to suggest that this pattern applies in general terms to all UK public debate surrounding the Iraq War - in other contexts we might expect to see, for example, advocates of war constructing their opponents as dispositionally inclined towards pacifism. However, it is notable that issues concerning what might typically be construed as attitudes to war in general, attitudes to a specific war (the Iraq war), to particular regimes or figures (e.g. Saddam Hussein; the US Government), and related abstract concepts (e.g. tyranny), were therefore bound up with a range of normative concerns regarding rationality and morality. Similarly, there was no distinction between attitude object and evaluative judgement - in discursive practice these speakers constructed the objects of their arguments with built-in evaluations. Nor was there a neat correspondence between general and particular evaluations. Indeed, the implication that one's support for the Iraq war was accompanied by a favourable attitude towards war in general was actively resisted in order to inoculate against being seen as habitually inclined to favour war. By contrast, for opponents of the war, 
in this context the issue of their general attitude to war was scarcely a 'live' concern, with the issue of their stance towards 'tyranny' seemingly more relevant.

\section{Discussion}

The analysis points to the potential of analysing people's evaluations of war and related concepts as they are articulated in discursive practice. This style of analysis is rather different from typical approaches to attitudes adopted in SPPR, but it has the distinct advantage of capturing evaluative formulations in situ in the context in which they occur. Specifically, discourse analysis emphasises the centrality of rhetorical context. For instance, it is notable that the most strident assertions of generally non-pro-war positions in this dataset were to be found amongst those speakers arguing in favour of military action in Iraq. In explaining this finding, we therefore need to attend to the rhetorical context of such positional statements, including an assessment of what these speakers are arguing against, and what counterarguments/criticisms they are anticipating. In this respect, it is perhaps unsurprising that advocates of a specific war should seek to mitigate the impression that they are habitually inclined to favour war, yet this observation is notably absent from much previous work on attitudes to war precisely because such work has tended not to analyse evaluations in discursive practice.

Also of note was the way in which evaluations were inseparable from constructions of the objects of evaluation (Potter \& Wetherell, 1987). Terms such as invasion, inspection, war, enforcement of a peace treaty, and others all illustrate the extent to which the particular terms used to describe the object of evaluation are themselves part and parcel of the evaluation. To describe military action as the enforcement of a peace treaty is to position oneself (and the position one advocates) 
as essentially morally normative, and the prosecution of war as something undertaken with a heavy heart (Durrheim, 1997; AUTHOR REF). Indeed, the extent to which speakers advocating military action sought to manage the morality of their position represents perhaps the most striking finding of the present analysis.

This discursive work to inoculate against the impression that an advocate of military action was dispositionally inclined to favour war stands in stark contrast to previous research (e.g. Cohrs \& Moschner, 2002) which has found a correlation between general and specific attitudes to war as measured on attitude scales. The present study suggests that in discursive practice, speakers may in fact work up a contrast between their general and specific positions in order to present a more persuasive case. Attention to the way in which people formulate claims or evaluations as either specific or general has long been a feature of discursive and rhetorical work in social psychology (e.g. Billig, 1985; Wiggins \& Potter, 2003), and the present analysis suggests that SPPR might benefit from viewing the generality or specificity of attitudes to war not as matters of a priori definition, but as situated social accomplishments which are formulated by speakers to perform particular context-bound social actions.

In this respect, the action-oriented nature of evaluations is also apparent. Speakers are not simply indicating their positions for the sake of it, but are doing so in order to achieve some end in the context of an argument regarding whether or not military action in Iraq is warranted. We might therefore suggest that when a social actor is indicating their position on some issue or other, we should always pay attention to the social action they are performing as they are doing so. In this respect, the utility of attitude scales is likely to be limited given that the action people are typically performing in such contexts is the action of filling in an attitude scale 
(although related actions such as self-presentation in the presence of a social science researcher are also potentially live concerns).

It is also worth noting that this line of argument draws attention to the way in which a discursive approach can help social psychology to transcend the dichotomy between attitudes and behaviour which constitutes one of the discipline's classic problems. In the DA approach, attitudes are re-specified as discursive evaluations, whilst discourse is itself seen as fundamentally action-oriented, meaning that evaluations are themselves seen as functional. The present paper is not the place to outline the implications of this line of argument fully, but nevertheless it does mean that rather than exploring how people's evaluations relate to their actions, we instead ask what actions their evaluations are performing.

Clearly many of these observations await further empirical scrutiny in different discursive contexts relating to war, peace and the military, but they nonetheless point to the quite different way in which a DA perspective approaches attitudes to war. It might be suggested that by removing people from the particular contexts in which they articulate evaluations we might hope to obtain a more objective or neutral response from them, and thus people's responses on attitude questionnaires might be seen as representing a better or truer assessment of people's 'real' attitudes. However, such a line of argument leads directly to one of the central claims of DA, which is that no articulation of an evaluation (or, indeed, any other discursive manoeuvre) can ever be acontextual. Making a mark on a questionnaire in a laboratory or lecture theatre is as much a context-bound discursive action as offering an evaluation of some course of action on a television talk show. Our grounds for accepting one as 'truer' than the other come only from the assumption that whereas the latter is likely to be heavily context contingent and influenced by a range of 
extraneous concerns, the former is in a fundamental sense obtained outside of a meaningful social context. Social psychologists of a range of different methodological and theoretical persuasions have questioned such assumptions (e.g. Baumeister, Vohs, \& Funder, 2007; Potter \& Wetherell, 1987; Tajfel, 1972). From a DA perspective, the questionnaire study is itself a rather particular (and possibly peculiar) social context, and thus the apparently confounding contextual influence of contexts such as the TV talk show are not seen as a problem to be controlled, but are instead to be treated as central to the analysis. Evaluations are made in context, and should be analyzed as such.

This suggests some deeper epistemological problems for any attempt to combine approaches from social psychology's methodological toolbox, and perhaps suggests that attempts to articulate SPPR which focus around the need for multiple methods need to go hand-in-hand with a concern for matters of epistemology. If they do not, then there is a danger that the radical questions posed by approaches such as DA go unanswered (and, indeed, unasked), as methodological pluralism is practiced from within a broadly (post-)positivistic epistemological framework. In this respect, a discourse analytic approach to SPPR provides not only an opportunity to broaden the field's methodological horizons, but - as is the case with social psychology more broadly - it offers an alternative vision of what the field might look like. 


\section{References}

Anderson, C. A., Benjamin Jr., A. J., Wood, P. K., \& Bonaccia, A. M. (2006).

Development and testing of the Velicer attitudes toward violence scale:

Evidence for a four-factor model. Aggressive Behavior, 32, 122-136. doi: 10.1002/ab.20112

Antaki, C., Condor, S., \& Levine, M. (1996). Social identities in talk: Speakers' own orientations. British Journal of Social Psychology, 35, 473-492.

Antaki, C., \& Widdicombe, S. (1998). Identities in talk. London: Sage.

Augoustinos, M. \& Every, D. (2010). Accusations and denials of racism: Managing moral accountability in public discourse. Discourse \& Society, 21, 251-256. DOI: $10.1177 / 0957926509360650$

Baumeister, R. F., Vohs, K. D., \& Funder, D. C. (2007). Psychology as the science of self-reports and finger movements: Whatever happened to actual behaviour? Perspectives on Psychological Science, 2, 396-403. doi: 10.1111/j.1745-6916.2007.00051.x

Billig, M. (1985). Prejudice, categorization and particularization: From a perceptual to a rhetorical approach. European Journal of Social Psychology, 15, 79-103. doi: 10.1002/ejsp.2420150107

Billig, M. (1996). Arguing and thinking: A rhetorical approach to social psychology ( $2^{\text {nd }}$ ed.). Cambridge: Cambridge University Press.

Billig, M., \& MacMillan, K. (2005). Metaphor, idiom and ideology: The search for 'no smoking guns' across time. Discourse and Society, 16, 459-480. doi: $10.1177 / 0957926505053050$

Blumberg, H. H., Hare, A. P., \& Costin, A. (2006). Peace psychology: A comprehensive introduction. Cambridge: Cambridge University Press. 
Cohrs, J. C. \& Moschner, B. (2002). Antiwar knowledge and generalized political attitudes as determinants of attitude toward the Kosovo war. Peace and Conflict: Journal of Peace Psychology, 8, 139-155. doi: 10.1207/S15327949PAC0802_03

Cohrs, J. C., Moschner, B., Maes, J., \& Kielmann, S. (2005). Personal values and attitudes toward war. Peace and Conflict: Journal of Peace Psychology, 11, 293-312. doi: 10.1207/s15327949pac1103_5

Condor, S., Figgou, L., Abell, J., Gibson, S. \& Stevenson, C. (2006). "They're not racist": Prejudice denial, mitigation and suppression in dialogue. British Journal of Social Psychology, 45, 441-462. doi: 10.1348/014466605X66817

Durrheim, K. (1997). Peace talk and violence: An analysis of the power of 'peace'. In A. Levett, A. Kottler, E. Burman, \& I. Parker (Eds), Culture, power and difference: Discourse analysis in South Africa (pp. 31-43). London: Zed Books.

Durrheim, K., \& Dixon, J. (2004). Attitudes in the fiber of everyday life: The discourse of racial evaluation and the lived experience of desegregation. American Psychologist, 59, 626-636. doi: 10.1037/0003-066X.59.7.626

Edwards, D. \& Potter, J. (1992). Discursive psychology. London: Sage.

Gibson, S. \& Abell, J. (2004). For Queen and country?: National frames of reference in the talk of soldiers in England. Human Relations, 57, 871-891. doi: $10.1177 / 0018726704045769$

Gibson, S. \& Condor, S. (2009). State institutions and social identity: National representation in soldiers' and civilians' interview talk concerning military service. British Journal of Social Psychology, 48, 313-336. doi: $10.1348 / 014466608 \times 349496$ 
Griffin, C. (2007). Being dead and being there: Research interviews, sharing hand cream and the preference for analysing 'naturally occurring data'. Discourse Studies, 9, 246-269. doi: 10.1177/1461445607075340

Herrera, M. (2003). Constructing social categories and seeking collective influence: Self-categorization and the discursive construction of conflict. International Journal of Psychology and Psychological Therapy, 3, 27-57.

Hewitt, J. P., \& Stokes, R. (1975). Disclaimers. American Sociological Review, 40, $1-11$.

Hutchby, I., \& Wooffitt, R. (1998). Conversation analysis: Principles, practices and applications. Cambridge: Polity.

Jackson, R. (2005). Writing the war on terrorism: Language, politics and counterterrorism. Manchester: Manchester University Press.

Lakoff, G. (1990). Metaphor and war: The metaphor system used to justify war in the Gulf. Unpublished manuscript, University of California at Berkeley.

McFarland, S. G. (2005). On the eve of war: Authoritarianism, social dominance, and Amercian students' attitudes toward attacking Iraq. Personality and Social Psychology Bulletin, 31, 360-367. doi: 10.1177/0146167204271596

McKenzie, K. (2001). Fact and the narratives of war: Produced undecidability in accounts of armed conflict. Human Studies, 24, 187-209. doi:

10.1023/A:1017543122464

Myers, G. (1999). Unspoken speech: Hypothetical reported discourse and the rhetoric of everyday talk. Text, 19, 571-590.

Pomerantz, A. M. (1986). Extreme case formulations: A way of legitimizing claims. Human Studies, 9, 219-229. doi:10.1007/BF00148128 
Potter, J. (1996). Representing reality: Discourse, rhetoric and social construction. London: Sage.

Potter, J. (1998). Discursive social psychology: From attitudes to evaluative practices. European Review of Social Psychology, 9, 233-266. doi: $10.1080 / 14792779843000090$

Potter, J., \& Edwards, D. (2001). Discursive social psychology. In W. P. Robinson \& H. Giles (Eds), The new handbook of language and social psychology (pp. 103-118). Chichester: John Wiley \& Sons.

Potter, J., \& Hepburn, A. (2005). Qualitative interviews in psychology: Problems and possibilities. Qualitative Research in Psychology, 2, 281-307. doi: 10.1191/1478088705qp045oa

Potter, J., \& Wetherell, M. (1987). Discourse and social psychology: Beyond attitudes and behaviour. London: Sage.

Roccato, M., \& Fedi, A. (2007). 'Not in my name'? The Italians and the war in Iraq. Journal of Community and Applied Social Psychology, 17, 229-236. doi: 10.1002/casp.905

Schäffner, C. \& Wenden, A. L. (1995). Language and peace. London: Routledge. Sherman, R. C. (1973). Dimensional salience in the perception of nations as a function of attitudes toward war and anticipated social interaction. Journal of Personality and Social Psychology, 27, 65-73. doi: 10.1037/h0034474

Stapel, D. A., \& Marx, D. M. (2007). Making sense of war: Using the interpretation comparison model to understand the Iraq conflict. European Journal of Social Psychology, 37, 401-420. doi: 10.1002/ejsp.369

Tajfel, H. (1972). Experiments in a vacuum. In J. Israel \& H. Tajfel (Eds), The context of social psychology (pp. 69-121). London: Academic Press. 
van Dijk, T. A. (1992). Discourse and the denial of racism. Discourse and Society, 3, 87-118. doi: 10.1177/0957926592003001005

van Dijk, T. A. (2005). War rhetoric of a little ally: Political implicatures and Aznar's legitimatization of the war in Iraq. Journal of Language and Politics, 4, 65-91.

Vollhardt, J. K., \& Bilali, R. (2008). Social psychology's contribution to the psychological study of peace: A review. Social Psychology, 39, 12-25. doi: $10.1027 / 1864-9335.39 .1 .12$

Wetherell, M. (1998). Positioning and interpretative repertoires: Conversation analysis and post-structuralism in dialogue. Discourse and Society, 9, 387412. doi: $10.1177 / 0957926598009003005$

Wiggins, S., \& Potter, J. (2003). Attitudes and evaluative practices: Category vs. item and subjective vs. objective constructions in everyday food assessments. British Journal of Social Psychology, 42, 513-531. doi: $10.1348 / 014466603322595257$

Wiggins, S., \& Potter, J. (2008). Discursive psychology. In C. Willig \& W. Stainton-Rogers (Eds.), The Sage handbook of qualitative research in psychology (pp. 73-90). London: Sage. 


\section{Appendix}

Transcription Conventions (adapted from Hutchby \& Wooffitt, 1998, pp. vi-vii)

(1.0) The number in parentheses indicates a time gap to the nearest tenth of a second.

(.) A dot enclosed in parentheses indicates a pause in the talk of less than twotenths of a second.

[ ] Square brackets between adjacent lines of concurrent speech indicate the onset and end of a spate of overlapping talk.

.hh A dot before an ' $h$ ' indicates speaker in-breath. The more h's, the longer the in-breath

hh An ' $h$ ' indicates an out-breath. The more h's, the longer the breath.

(( )) A description enclosed in double parentheses indicates a non-verbal activity. For example, ((pointing)). Alternatively double parentheses may enclose the transcriber's comments on contextual or other features.

- $\quad$ A dash indicates the sharp cut-off of the prior word or sound.

: Colons indicate that the speaker has stretched the preceding sound. The more colons the greater the extent of stretching.

! Exclamation marks are used to indicate an animated or emphatic tone.

that Underlined fragments indicate speaker emphasis.

$\circ$ Degree signs are used to indicate that the talk they encompass is spoken noticeably quieter than the surrounding talk.

$>\quad$ 'More than' and 'less than' signs indicate that the talk they encompass was produced noticeably quicker than the surrounding talk. 
Speaker identification: DD = David Dimbleby (Host); SH = Simon Heffer (on-screen caption: Columnist, Daily Mail); CDW = Clarissa Dickson-Wright (on-screen caption: Broadcaster and cook); Beatrix Campbell (on-screen caption: Writer); TC = Tim Collins (on-screen caption: Shadow Transport Secretary); CA = Clive Anderson (on-screen caption: Broadcaster). Audience members are identified by the letter ' $A$ ' followed by a numeral which indicates the order in which they responded in the discussion of Iraq in any given programme. Collective audience responses (e.g. applause) are identified by 'Au'. 